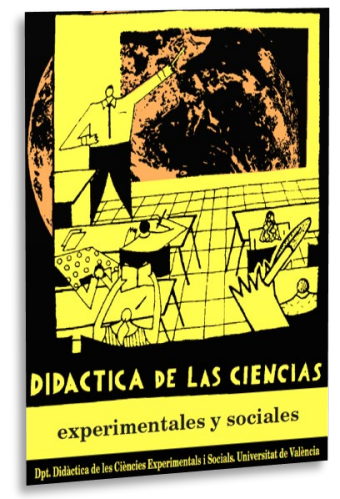

\title{
Evaluación de una secuencia de enseñanza de termoquímica para la formación de profesores
}

\author{
Evaluation of a thermochemistry teaching \\ sequence for teacher training
}

DOI: $10.7203 / D C E S .38 .15577$

\author{
Carles Furió Mas \\ Universitat de València, carles.furio@uv.es \\ Cristina Furió Gómez \\ Universitat de València, cristina.furio@uv.es \\ Jenaro Guisasola Aranzabal \\ Universidad del País Vasco, jenaro.guisasola@ehu.es
}

\begin{abstract}
RESUMEN: El objetivo de este trabajo consiste en diseñar una secuencia de aprendizaje sobre termoquímica como investigación guiada para el bachillerato, implementarla en dos cursillos de Didáctica de las Ciencias para futuros profesores de Física y Química y evaluar su impacto en la mejora del conocimiento termoquímico de estos. Participaron 35 estudiantes de último curso de Física, Química e Ingeniería Química, que discutieron en pequeños grupos sobre la secuencia de enseñanza propuesta en forma de programa de actividades durante 12 sesiones de 2 horas. Para ver la eficacia de la secuencia se aplicó un diseño pre-test/post-test basado en un cuestionario de 5 preguntas abiertas donde había que predecir y explicar los efectos térmicos en 3 fenómenos físicos y 2 químicos. Los resultados muestran que el conocimiento termoquímico de los futuros profesores mejora, si bien el tamaño del efecto logrado no ha sido el mismo en cada uno de los fenómenos.
\end{abstract}

Palabras Clave: investigación, futuros profesores, termoquímica, aprendizaje como investigación guiada, evaluación.

ABSTRACT: The objective of this paper is to design a teaching sequence about thermochemistry as a guided inquiry for High School, implement it in two training courses for preservice Physics and Chemistry teachers and evaluate its impact on the improvement of their knowledge about thermochemistry. Thirty-five undergraduate students of the last course of Physics, Chemistry and Chemical Engineering participated and discussed in small groups the proposed sequence as an activity program for 12 two-hour sessions. To test the effectiveness of the teaching sequence, a pre-test/post-test design was applied based on a questionnaire with 5 open-ended questions in which they had to predict and explain the thermal effects in 3 physical and 2 chemical phenomena. The results show that the thermochemical knowledge of future teachers improves, although the size effect achieved has not been the same for each phenomenon.

KEYWORDS: research, preservice teachers, thermochemistry, guided research-based learning, assessment.

Fecha de recepción: julio de 2019

Fecha de aceptación: febrero de 2020 


\section{INTRODUCCIÓN}

Se han realizado muchos estudios respecto a las creencias y dificultades de los profesores en formación sobre la ciencia y los métodos de enseñanza. Por otra parte, son conocidos el informe americano del National Research Council (N.R.C., 2000) relativo a una nueva manera de enseñar ciencia en secundaria para el siglo XXI y el de la Comisión Europea (Rocard et al., 2007) que enfatiza la necesidad social y económica de alfabetizar científicamente a los futuros ciudadanos mejorando los métodos de enseñar ciencia. Estos nuevos enfoques se ha comprobado que no solo aumentan la motivación de los estudiantes sino que también favorecen su aprendizaje. Sin embargo, el mismo N.R.C. (2011) denuncia que los resultados de investigación siguen estando ausentes en los currículos de la formación inicial de profesores de secundaria de ciencias como ya sucedía hace más de 25 años en la formación de maestros europeos (Blackburn y Moissan, 1986). Es decir, sigue existiendo la brecha entre teoría y práctica no solo entre investigadores y profesores en activo sino también en la formación inicial del profesorado de ciencias que suele realizarse en la Universidad.

Una de las asignaturas pendientes en esta formación es la integración de los conocimientos científicos a enseñar con los relativos a la preparación práctica en la docencia. En un artículo anterior (Furió-Más, Solbes Matarredona y Furió Gómez, 2008) proponíamos un conjunto de estrategias a utilizar en la formación de profesores, entre las cuales, destacábamos la necesidad de impulsar la reflexión didáctica explícita de los profesores mediante la vivencia de propuestas innovadoras con el fin de experimentar cómo se puede orientar de manera más efectiva la enseñanza. Será, pues, importante que en la formación inicial de los profesores de Ciencias se haga vivir a los estudiantes un modelo de enseñanza basado en la indagación de manera isomorfa a cómo habrían de implementarlo en el aula. Así los futuros profesores podrían valorar la eficiencia de una enseñanza basada en los resultados de la investigación e interesarlos en la relación teoría-práctica. Y, si es posible, convendría seleccionar propuestas con contenidos reconocidos como difíciles por los propios estudiantes universitarios tales como los relativos a la termodinámica y la termoquímica. En este contexto hay que tener en cuenta, en particular, las dificultades en la energía interna., entalpía y conceptos relacionados (trabajo y calor) así como en la primera ley de la termodinámica. En la literatura hay revisiones recientes como la de Bain, Moon, Mack y Towns (2014) centrada en la investigación sobre el aprendizaje y la enseñanza de la termodinámica y termoquímica en estudiantes universitarios donde se presentan también resultados sobre sus concepciones y razonamientos cuando usan el modelo atómico de la materia (MAM). En esta revisión se citan artículos específicos sobre dificultades en el aprendizaje de la primera ley de la termodinámica en estudiantes de Física (Loverude, Kautz y Heron, 2002) y de Química (Hadfield y Wieman, 2010) así como en el concepto de entalpía y termoquímica (Nilson y Niedderer, 2014).

El objeto principal de este trabajo consiste en diseñar e implementar una secuencia de enseñanza basada en el modelo de aprendizaje como investigación guiada (Guisasola, Furió y Ceberio, 2008) y cuestionar si ayuda a superar dificultades en termoquímica a una muestra de estudiantes universitarios del último curso de las carreras de Física, Química e Ingeniería Química que asistían a un cursillo de Didáctica de las Ciencias para formarse como profesores de Física y Química de Bachillerato. Como parte del cursillo se presentaba y debatía una secuencia de enseñanza sobre termoquímica a alumnos de Bachillerato. Esta secuencia de enseñanza basada en la investigación es semejante a las que ya hemos aplicado anteriormente en la enseñanza del campo eléctrico en el Bachillerato (17 años) (Furió, Guisasola, Almudí y Ceberio, 2003) o en la del concepto de cantidad de sustancia y de mol (Furió, Azcona y Guisasola, 2006) en alumnos del mismo nivel. El diseño de la nueva secuencia, desarrollada por los investigadores, en forma de programa de actividades, se presenta como ejemplo de aprendizaje como investigación orientada en la clase de Didáctica de las Ciencias donde los futuros profesores de Física y Química distribuidos en grupos de 3 o 4 han de ir debatiendo las actividades para aplicar los conocimientos científicos que recuerden 
sobre el tema y, al mismo tiempo, elucidar sus dificultades. Por ello la primera cuestión del problema investigado es:

1. ¿Qué conocimientos sobre la primera ley y el concepto de entalpía recuerdan los futuros profesores de Física y Química cuando han de explicar el efecto mecánico y térmico en procesos físicos y químicos y qué dificultades tienen?

Y, una vez se haya implementado la propuesta innovadora a estos estudiantes universitarios se cuestionará:

2. ¿En qué medida han mejorado sus conocimientos sobre la primera ley y el concepto de entalpía al finalizar la implementación de la secuencia de enseñanza?

\section{1. ¿Qué significa tener una comprensión adecuada de la transferencia de energía entre sistemas cuando se producen cambios físicos o químicos?}

Una adecuada comprensión de cómo se transfiere la energía en procesos físicos y químicos requiere un cierto dominio de los conceptos de calor, trabajo, energía interna, E, y entalpía, H, así como de la primera ley de la Termodinámica y el principio de conservación de energía.

En el caso de que el sistema no esté aislado y sólo se consideren sus funciones de estado (E y $\mathrm{H})$ y las variables de proceso $\left(\mathrm{Q}_{\text {ext }} \mathrm{y} \mathrm{W}_{\text {ext }}\right)$ como transferencias de energía con otros sistemas se aplicará la primera ley de la termodinámica que se puede resumir como: $\Delta \mathrm{E}=\mathrm{Q}_{\mathrm{ext}}+\mathrm{W}_{\mathrm{ext}}$ donde $\mathrm{Q}_{\mathrm{ext}}$ y $\mathrm{W}_{\text {ext }}$ son transferencias de energía, respectivamente, en forma de calor y de trabajo mecánico realizados sobre el sistema. Expresión que es válida siempre que en el proceso no se realice otro tipo de trabajo (ni eléctrico ni técnico), ni intervengan radiaciones luminosas. Y, en cualquier proceso isobaro se introduce la nueva función entalpía $(\mathrm{H}=\mathrm{E}+\mathrm{p} \cdot \mathrm{V})$ que al diferenciarla se obtiene $\mathrm{dH}=\mathrm{dE}$ $+\mathrm{d}(\mathrm{p} \cdot \mathrm{V})=\mathrm{dE}+\mathrm{p} \cdot \mathrm{dV}+\mathrm{V} \cdot \mathrm{dp}[1]$ y que al integrarla a presión constante resulta: $\Delta \mathrm{H}=\Delta \mathrm{E}+\mathrm{p} \cdot \Delta \mathrm{V}$ [2] donde el último sumando de [2] es el trabajo asociado a la expansión/compresión realizado por o sobre el sistema. En este caso la primera ley adquiere la forma: $\Delta \mathrm{H}^{\circ}{ }_{r}=\mathrm{Q}_{\mathrm{p}}$, donde $\mathrm{Q}_{\mathrm{p}}$ es el calor externo a presión constante y $\Delta \mathrm{H}^{\mathrm{o}}$ la variación de entalpía estándar del sistema que ha de explicar el efecto térmico producido. En el caso de que el proceso sea isocoro al integrar se obtendría $\Delta \mathrm{H}=\Delta \mathrm{E}$ $+\mathrm{V} \cdot \Delta \mathrm{p}$ [3] donde el último sumando de [3] es el denominado 'trabajo técnico' realizado para elevar la presión del sistema a volumen constante (Nilsson y Niedderer, 2014). Conviene advertir que no se han de confundir las dos funciones introducidas $\mathrm{E}$ y $\mathrm{H}$ aunque se midan en la mismas unidades si bien en la mayoría de libros de texto suelen utilizarse como sinónimas.

En termoquímica el cálculo teórico de $\Delta \mathrm{H}^{\circ}{ }_{\mathrm{r}}$ se puede obtener macroscópicamente a partir del esquema del proceso físico o químico, debidamente ajustado, teniendo en cuenta las entalpías estándar de formación de los productos $\left(\mathrm{H}_{\mathrm{f}, 2}^{\mathrm{o}}\right)$ y reactivos $\left(\mathrm{H}_{\mathrm{f}, 1}^{\mathrm{o}}\right)$ según la ecuación: $\Delta \mathrm{H}_{\mathrm{r}}^{\mathrm{o}}=\sum \mathrm{H}_{\mathrm{f}, 2}^{\mathrm{o}}$ $\sum \mathrm{H}_{\mathrm{f}, 1}^{\mathrm{o}}$ [4]. En el caso de que el proceso químico tenga lugar en fase gaseosa, el cálculo de $\Delta \mathrm{H}_{\mathrm{r}}^{\mathrm{o}}$ también puede obtenerse sumando las entalpías promedio de los enlaces interatómicos que se rompen en las moléculas de los reactivos (consideradas positivas porque son las entalpías necesarias para romper estos enlaces que se ha de aportar al sistema desde el exterior) y las de los enlaces que se forman en los productos (consideradas negativas porque son liberadas por el propio sistema). Cuando hay que utilizar razonamientos en este nivel submicroscópico (MAM) se ha visto que los profesores en formación tienen dificultades debido al uso de modelos mentales particulares como, por ejemplo, considerar que en la ruptura de enlaces se libera energía por el sistema (Al-Baluschi, 2009).

En el caso de que el sistema esté aislado se ha de cumplir el principio de conservación de la energía: $\Delta \mathrm{E}=0$, donde $\mathrm{E}$ es la energía total del sistema. En el supuesto más sencillo de que el sistema esté formado por dos subsistemas, 1 y 2 , cuyas partículas interaccionan mecánicamente, el principio de conservación de la energía puede aplicarse en el nivel submicroscópico, por ejemplo, como: [ $\Delta \mathrm{E}_{\mathrm{k}, 1}$ $\left.+\Delta \mathrm{E}_{\mathrm{p}, 1}\right]+\left[\Delta \mathrm{E}_{\mathrm{k}, 2}+\Delta \mathrm{E}_{\mathrm{p}, 2}\right]=0$, donde $\Delta \mathrm{E}_{\mathrm{k}, 1}$ es la variación de las energías cinéticas asociadas a las partículas del subsistema 1 en el proceso y $\Delta \mathrm{E}_{\mathrm{p}, 1}$ representa la variación de las energías potenciales 
asociadas a las uniones entre las partículas del mismo subsistema 1. Lo mismo se aplica a las variaciones de las energías cinéticas y potenciales en el subsistema 2.

\section{2 ¿Qué aprendizajes han de adquirir los estudiantes de Bachillerato en la enseñanza de la Termoquímica y cuáles son las posibles dificultades que se pueden presentar?}

En la tabla 1 se presenta el conjunto de indicadores de aprendizaje que ha de adquirir un estudiante para poder resolver con éxito el análisis de una situación problemática en el contexto de transferencias energéticas o entálpicas entre dos sistemas superando las dificultades que puedan surgir. El apartado 1 se refiere a la necesidad de que el estudiante se familiarice previamente con el fenómeno, o sea ha de saber cómo varía cualitativamente la temperatura del sistema al producirse el cambio en el supuesto más frecuente de que el proceso sea adiabático. Una de las primeras dificultades que se pueden presentar es no saber si el proceso es endotérmico o exotérmico. El estudiante suele recurrir al signo de $\Delta \mathrm{H}^{\circ}{ }_{\mathrm{r}}$ cuando se incluye en el ítem (Nilson y Niedderer, 2014; Granville, 1985). En el indicador 2 el estudiante ha de saber analizar la situación recurriendo a un modelo termodinámico (Kermen y Meheut, 2011) sea macroscópico o submicroscópico. Este indicador 2 es complejo ya que requiere saber no solamente cómo es el proceso (adiabático, isotermo, etc.) sino, además, delimitar cuáles son los sistemas que interaccionan y si se transfiere entre ellos energía en forma de calor y/o de trabajo. En este indicador 2 se pueden presentar varias dificultades como, por ejemplo, olvidarse del entorno como uno de los sistemas que intervienen y sobre el cuál se realizará trabajo cuando se expansione un gas (Loverude et al., 2002; Furió-Gómez y Furió-Más, 2016). Otros razonamientos espontáneos detectados por la investigación son el reduccionismo funcional (Viennot, 1992), la fijación funcional (Furió, Calatayud, Bárcenas y Padilla, 2000) o transposiciones inadecuadas usadas en Química (Talanquer, 2006). Viennot (1992) define el reduccionismo funcional como el que manifiestan los estudiantes cuando afirman que la presión (o el volumen) de un gas solo depende de una única variable. Furió et al. (2000) conciben la fijación funcional como un modelo de razonamiento del alumno que favorece el aprendizaje repetitivo como única estrategia sin tener sentido físico o químico para él. Por ejemplo, cuando el estudiante considera que la proporción de las masas de combinación de dos reaccionantes son dos cantidades fijas que siempre han de reaccionar. Talanquer (2006) ha observado que los estudiantes de Química tienden a aplicar propiedades macroscópicas al nivel submicroscópico como, por ejemplo, cuando asocian 'la temperatura a una molécula'. En el apartado 3 se enfatizan los aprendizajes relativos al modelo termodinámico esquematizado en Furió-Gómez y Furió-Más (2016). El apartado 4 de la tabla 1 contiene los indicadores relativos a la interpretación submicroscópica de la variación entálpica del sistema teniendo en cuenta la ruptura y formación de enlaces entre partículas según el modelo elemental de reacción química (Treagust, Chittleborough y Mamiala, 2003). Estas modelizaciones macroscópica y submicroscópica son complementarias y, como indican los expertos, favorecen en los estudiantes la comprensión energética en los procesos físicos y químicos (Atkins, 1992).

\section{SECUENCIA DE ENSEÑANZA}

Una vez analizados por los investigadores las principales dificultades en el desarrollo de la Termoquímica se eligieron los contenidos del currículum sobre el tema ¿Cómo explicar los efectos mecánicos y térmicos en procesos físico-químicos? que habrían de enseñarse en la Termoquímica de $2^{\circ}$ de Bachillerato. Contenidos que vienen en forma de situaciones problemáticas en la primera columna de la tabla 2 y que serán el hilo conductor para desarrollar el programa de actividades a discutir en pequeños grupos por los futuros profesores. En la segunda columna están las ideas y procedimientos que han de aprender los estudiantes y en la tercera columna las valoraciones y explicaciones que han de realizar basándose en los conocimientos científicos aprendidos según el modelo de aprendizaje como investigación guiada (Guisasola, Furió y Ceberio, 2008). 
TABLA 1. Indicadores de aprendizajes a lograr en Termoquímica y posibles dificultades de los estudiantes.

\begin{tabular}{|c|c|c|}
\hline $\mathbf{N}^{\mathbf{0}}$ & Indicadores de aprendizaje & Posibles dificultades \\
\hline 1 & $\begin{array}{l}\text { Familiarizarse empíricamente con el } \\
\text { fenómeno objeto de estudio. En particular, } \\
\text { saber describir la fenomenología de los } \\
\text { cambios clasificándolos en exotérmicos y } \\
\text { endotérmicos. }\end{array}$ & $\begin{array}{l}\text { No saben describir cuándo se considera que el } \\
\text { proceso es endotérmico y cuando exotérmico. En } \\
\text { particular, si no se aporta el signo de } \Delta \mathrm{H}^{\circ} \text { del } \\
\text { proceso en el ítem (Granville, 1985; Nilsson y } \\
\text { Niedderer, 2014). }\end{array}$ \\
\hline 2 & $\begin{array}{l}\text { Saber analizar cualitativamente una situación } \\
\text { problemática con el fin de precisarla. En } \\
\text { particular: } \\
\quad \text {-Saber delimitar los sistemas que } \\
\text { interaccionan. } \\
\quad \text {-Saber cómo es el proceso (adiabático, } \\
\text { isotermo, etc.). } \\
\text {-Saber analizar si se realiza trabajo o } \\
\text { transfiere calor entre sistemas o entre partes de } \\
\text { un único sistema. } \\
\quad \text {-Saber que en un proceso adiabático el } \\
\text { sistema no transfiere energía en forma de calor } \\
\text { al exterior pero ello no ha de significar que no } \\
\text { pueda variar su temperatura al hacer trabajo } \\
\text { sobre un segundo sistema. }\end{array}$ & $\begin{array}{l}\text { No saben delimitar los sistemas que } \\
\text { interaccionan. Los estudiantes suelen olvidar o } \\
\text { tratar incorrectamente el trabajo de expansión } \\
\text { (Loverude et al., 2002; (Furió-Gómez y Furió- } \\
\text { Más, 2016). } \\
\text { Se pueden presentar fijaciones funcionales: por } \\
\text { ejemplo, creer que en la evaporación de un } \\
\text { líquido siempre se mantiene constante su } \\
\text { temperatura como en la ebullición a P constante } \\
\text { o creer que el aislamiento térmico de un sistema } \\
\text { implica que, aparte del calor, no hay otras formas } \\
\text { de transferir energía entre sistemas (Furió, } \\
\text { Calatayud, Bárcenas y Padilla, 2000; Furió- } \\
\text { Gómez y Furió-Más, 2016). }\end{array}$ \\
\hline 3 & $\begin{array}{l}\text { Saber aplicar la modelización termodinámica } \\
\text { para explicar qué ocurre con la energía o la } \\
\text { entalpía cuando dos sistemas interaccionan. }\end{array}$ & \\
\hline 3.1 & $\begin{array}{l}\text { Superar dificultades sobre conceptos previos } \\
\text { tales como: } \\
\text {-Saber diferenciar calor de temperatura. } \\
\text {-Saber que la temperatura es una magnitud } \\
\text { estadística del conjunto de partículas del } \\
\text { sistema. } \\
\text {-Saber que el calor y el trabajo son formas de } \\
\text { transferir energía entre sistemas. }\end{array}$ & $\begin{array}{l}\text { Transposición submicroscópica errónea al } \\
\text { atribuir temperatura a una molécula aislada o, por } \\
\text { ejemplo, cuando el estudiante cita 'las moléculas } \\
\text { calientes' (Talanquer, 2006). } \\
\text { Considerar que el calor o el trabajo son formas de } \\
\text { energía contenidas en el sistema (Doménech, } \\
\text { Limiñana y Menargues, 2013). }\end{array}$ \\
\hline 3.2 & $\begin{array}{l}\text { Saber el significado cualitativo de energía } \\
\text { interna, E, de un sistema, diferenciarlo del de } \\
\text { calor y saber de qué factores puede depender. }\end{array}$ & $\begin{array}{l}\text { Identificar la energía interna, E, con el calor o con } \\
\text { la temperatura del sistema (Doménech et al., } \\
\text { 2013). } \\
\text { E solamente depende de la sustancia o de la } \\
\text { temperatura (Furió-Gómez y Furió-Más, 2016). }\end{array}$ \\
\hline 3.3 & $\begin{array}{l}\text { Saber aplicar correctamente el primer } \\
\text { principio de la Termodinámica o el de } \\
\text { conservación de la energía en cambios físicos } \\
\text { y químicos. }\end{array}$ & $\begin{array}{l}\text { No saber en general aplicar el primer principio de } \\
\text { Termodinámica ni el de conservación de la } \\
\text { energía (Loverude et al., 2002; Solbes, Guisasola } \\
\text { y Tarín, 2009). }\end{array}$ \\
\hline 3.4 & $\begin{array}{l}\text { Saber el significado cualitativo de la entalpía, } \\
\mathrm{H} \text {, del sistema como nueva función de estado, } \\
\text { su campo de validez y la medida de } \Delta \mathrm{H} \text { en } \\
\text { procesos isobaros. }\end{array}$ & $\begin{array}{l}\text { H solamente depende de la sustancia o de la } \\
\text { temperatura (Furió-Gómez y Furió-Más, 2016). } \\
\text { Se asocia entalpía del sistema con el calor } \\
\text { producido o recibido y no se usa como función de } \\
\text { estado (Barlet y Mastrot, 2000). } \\
\text { La } \Delta \mathrm{H} \text { en un cambio siempre equivale a } \mathrm{Q}_{\mathrm{p}} \text { sin } \\
\text { tener en cuenta su campo de validez. Por ejemplo, } \\
\text { esta afirmación no es válida si se realiza trabajo } \\
\text { eléctrico o emiten radiaciones luminosas en el } \\
\text { proceso. }\end{array}$ \\
\hline
\end{tabular}


TABLA 1 (CONT.). Indicadores de aprendizajes a lograr en Termoquímica y posibles dificultades de los estudiantes.

\begin{tabular}{|c|l|l|}
\hline $\mathbf{N}^{\mathbf{0}}$ & \multicolumn{1}{|c|}{ Indicadores de aprendizaje } & \multicolumn{1}{c|}{ Posibles dificultades } \\
\hline 4 & $\begin{array}{l}\text { Saber aplicar la modelización atómica } \\
\text { (M.A.M.) para explicar qué ocurre con la } \\
\text { energía o la entalpía cuando interaccionan las } \\
\text { sustancias en un proceso físico o químico. }\end{array}$ & \\
\hline \multirow{4}{*}{4.1} & $\begin{array}{l}\text { Saber aplicar el MAM para explicar estos } \\
\text { fenómenos térmicos en cambios físicos y } \\
\text { químicos. En particular, saber utilizar } \\
\text { correctamente el modelo elemental de } \\
\text { reacción química. }\end{array}$ & $\begin{array}{l}\text { Los estudiantes universitarios de Ciencias no } \\
\text { suelen hacer interpretaciones submicroscópicas } \\
\text { en este dominio (Bain et al., 2014). Y cuando lo } \\
\text { hacen utilizan, a veces, transferencias } \\
\text { macroscópicas inadecuadas como, por ejemplo, } \\
\text { atribuir la temperatura de un gas a los choques } \\
\text { o fricción entre sus partículas (Talanquer, } \\
\text { 2006). }\end{array}$ \\
\hline 4.2 & $\begin{array}{l}\text { Saber interpretar submicroscópicamente el } \\
\text { aH de un proceso mediante el balance } \\
\text { entálpico teniendo en cuenta la ruptura de } \\
\text { enlaces en los reactivos y la formación de } \\
\text { nuevos enlaces en los productos tanto en } \\
\text { cambios exotérmicos como endotérmicos. }\end{array}$ & $\begin{array}{l}\text { Atribuirel desprendimiento de calor a la ruptura } \\
\text { formación o asociar el aporte de energía con la } \\
\text { Subramaniam, 2013; Furió-Gómez y Furió- } \\
\text { Más, 2016). }\end{array}$ \\
\hline
\end{tabular}

Fuente: elaboración propia

TABLA 2. Secuencia de situaciones problemáticas para el estudio energético y/o entálpico de los efectos mecánicos y/o térmicos que suceden en los cambios físicos y químicos.

\begin{tabular}{|c|c|c|}
\hline $\begin{array}{l}\text { Secuencia de contenidos como } \\
\text { situaciones problemáticas a } \\
\text { plantear en Termoquímica }\end{array}$ & $\begin{array}{l}\text { Procedimientos sobre la } \\
\text { Ciencia a aprender por los } \\
\text { alumnos }\end{array}$ & $\begin{array}{lcc}\text { Valoraciones, } & \text { descripciones de } \\
\text { fenómenos } & \text { y } & \text { posibles } \\
\text { explicaciones } & & \end{array}$ \\
\hline $\begin{array}{l}\text { 1. ¿Qué interés y utilidad puede } \\
\text { tener el estudio de los cambios } \\
\text { energéticos que ocurren en } \\
\text { cambios físicos y químicos? }\end{array}$ & $\begin{array}{l}\text { La ciencia se interesa por los } \\
\text { fenómenos naturales y sus } \\
\text { implicaciones sociales. El } \\
\text { origen del interés por un } \\
\text { fenómeno o un hecho } \\
\text { conocido es muy variado: la } \\
\text { propia ciencia, problemas } \\
\text { locales o globales... }\end{array}$ & $\begin{array}{l}\text { Ejemplos: Valoración de la } \\
\text { obtención y uso de la energía por las } \\
\text { implicaciones científicas, tecno- } \\
\text { lógicas y sociales que tiene y, en } \\
\text { particular, por las repercusiones } \\
\text { ambientales como, por ejemplo, el } \\
\text { cambio climático del planeta } \\
\text { producido por la actividad humana. }\end{array}$ \\
\hline $\begin{array}{l}\text { 2. ¿Qué puede pasar, desde el } \\
\text { punto de vista energético, en un } \\
\text { cambio físico o químico? } \\
\text { En este tema, se pondrá el énfasis } \\
\text { en la descripción y explicación de } \\
\text { los efectos mecánicos y/o } \\
\text { térmicos producidos en los } \\
\text { cambios físico-químicos. } \\
\text { Explicación basada en } \\
\text { modelizaciones que han de } \\
\text { (re)construir posteriormente los } \\
\text { estudiantes. }\end{array}$ & $\begin{array}{l}\text { Este interés hace que los } \\
\text { científicos centren su atención } \\
\text { en observaciones empíricas } \\
\text { y/o informaciones sobre los } \\
\text { fenómenos objeto de estudio, } \\
\text { en particular, los que se } \\
\text { realizan rápidamente } \\
\text { (adiabáticos). Si hay efecto } \\
\text { térmico observable, el alumno } \\
\text { ha de describir el tipo de } \\
\text { proceso (exotérmico o } \\
\text { endotérmico) y ser capaz de } \\
\text { diseñar y realizar } \\
\text { experimentos para medir el } \\
\text { calor producido. }\end{array}$ & $\begin{array}{l}\text { En este estudio el alumno tendrá } \\
\text { como objetivo general de } \\
\text { aprendizaje delimitar } \\
\text { macroscópicamente cuáles son los } \\
\text { sistemas que interaccionan y saber } \\
\text { analizar si hay transferencias } \\
\text { energéticas en forma de calor o de } \\
\text { trabajo mecánico entre ellos para } \\
\text { llegar a explicar los posibles efectos } \\
\text { mecánico y térmico observados. }\end{array}$ \\
\hline
\end{tabular}


TABLA 2 (CONT.). Secuencia de situaciones problemáticas para el estudio de los efectos mecánicos y/o térmicos que suceden en los cambios físicos y químicos.

\begin{tabular}{|c|c|c|}
\hline $\begin{array}{l}\text { Secuencia de contenidos como } \\
\text { situaciones problemáticas a } \\
\text { plantear en Termoquímica }\end{array}$ & $\begin{array}{l}\text { Procedimientos sobre la } \\
\text { Ciencia a aprender por los } \\
\text { alumnos }\end{array}$ & $\begin{array}{lcr}\text { Valoraciones, } & \text { descripciones de } \\
\text { fenómenos } & \text { y } & \text { posibles } \\
\text { explicaciones } & & \end{array}$ \\
\hline $\begin{array}{l}\text { 3. ¿Cuál es el problema que se } \\
\text { pretende resolver en el estudio } \\
\text { termodinámico de un proceso físico } \\
\text { o químico? }\end{array}$ & $\begin{array}{l}\text { La ciencia, al plantearse un } \\
\text { problema, empieza por } \\
\text { precisarlo, acotarlo haciendo } \\
\text { que sea asequible la búsqueda } \\
\text { de solución teórica mediante } \\
\text { el uso de modelos. }\end{array}$ & $\begin{array}{l}\text { Adquisición de una concepción } \\
\text { preliminar del estudio a realizar. El } \\
\text { problema consistirá en responder: } \\
\text { ¿Cómo explicar el efecto mecánico } \\
\text { y/o térmico que se produce en un } \\
\text { cambio físico o químico? }\end{array}$ \\
\hline $\begin{array}{l}\text { 4. ¿Cómo interpretar el efecto } \\
\text { mecánico y/o térmico que se } \\
\text { observa en un cambio físico o } \\
\text { químico? } \\
\text { Necesidad de introducir, a título de } \\
\text { hipótesis, una primera función } \\
\text { termodinámica como la energía } \\
\text { interna, E, del sistema para explicar } \\
\text { las transferencias de energía en } \\
\text { forma de calor, Qext, y/o trabajo, } \\
\mathrm{W}_{\text {ext, aplicados por o sobre otro }} \\
\text { sistema o entre partes del mismo } \\
\text { sistema. }\end{array}$ & $\begin{array}{l}\text { Una vez se han adquirido } \\
\text { referentes empíricos del } \\
\text { fenómeno a estudiar y se ha } \\
\text { precisado la situación } \\
\text { problemática, se aborda su } \\
\text { solución mediante la emisión } \\
\text { de hipótesis basada en un } \\
\text { modelo termodinámico. Se } \\
\text { supondrá que el sistema tiene } \\
\text { una E, se idearán estrategias } \\
\text { adecuadas que solucionen el } \\
\text { problema para explicar } \\
\text { macroscópica } \\
\text { submicroscópicamente } \text { el } \\
\text { efecto térmico. }\end{array}$ & $\begin{array}{l}\text { Saber el significado cualitativo de } \\
\text { energía interna de un sistema, E, y de } \\
\text { qué características (físicas, químicas } \\
\text { o electromagnéticas) del mismo } \\
\text { depende. } \\
\text { Saber diferenciar la } \Delta E \text { del sistema } \\
\text { del calor o de la temperatura del } \\
\text { propio sistema. } \\
\text { Atención a otros posibles errores } \\
\text { conceptuales de la energía interna } \\
\text { del sistema como, por ejemplo, } \\
\text { confundirla con el 'contenido } \\
\text { calorífico' del sistema o con la } \\
\text { entropía. }\end{array}$ \\
\hline $\begin{array}{l}\text { 5. ¿Cómo relacionar en el cambio } \\
\text { producido la variación de la nueva } \\
\text { función, } \Delta \mathrm{E} \text {, del sistema con el } \\
\text { calor, Q Q ext, y el trabajo, } \mathrm{W}_{\text {ext }} \text {, } \\
\text { realizado sobre el sistema? }\end{array}$ & $\begin{array}{l}\text { Saber establecer en procesos } \\
\text { físicos o químicos la relación } \\
\text { de la variación de la energía } \\
\text { interna, } \Delta \mathrm{E} \text {, que sufre el } \\
\text { sistema con el calor, Qext, y/o } \\
\text { el trabajo, } \mathrm{W}_{\text {ext, externos }} \\
\text { aplicados por un segundo } \\
\text { sistema (primera ley de la } \\
\text { Termodinámica). }\end{array}$ & $\begin{array}{l}\text { Saber aplicar la primera ley de la } \\
\text { Termodinámica a situaciones } \\
\text { fenomenológicas conocidas. O sea, } \\
\text { saber relacionar la } \Delta \mathrm{E} \text { del sistema y } \\
\text { las transferencias de energía en } \\
\text { forma de calor y trabajo mecánico } \\
\text { entre partes del mismo sistema o con } \\
\text { otro sistema. }\end{array}$ \\
\hline $\begin{array}{l}\text { 6. ¿Para qué y cómo introducir una } \\
\text { segunda función, la entalpía } \mathrm{H} \text { de } \\
\text { un sistema, que facilite la } \\
\text { explicación de los efectos } \\
\text { mecánicos y térmicos en los } \\
\text { procesos físicos y químicos que } \\
\text { ocurren a presión constante? }\end{array}$ & $\begin{array}{l}\text { Saber el significado } \\
\text { cualitativo de la "entalpía de } \\
\text { un sistema", H, como la } \\
\text { función a usar en procesos } \\
\text { isobaros que incluye la } \\
\text { función energía interna, E, y la } \\
\text { capacidad de producir trabajo } \\
\text { mecánico por el sistema } \\
\text { (función p.V). }\end{array}$ & $\begin{array}{l}\text { Saber diferenciar y relacionar la } \\
\text { entalpía de la energía interna del } \\
\text { sistema. }\end{array}$ \\
\hline $\begin{array}{l}7 . \quad \text { ¿Cómo } \\
\text { submicroscopicamente } \\
\text { variaciones entálpicas, } \Delta \mathrm{H}_{\mathrm{r}}^{\mathrm{o}} \text {, que } \\
\text { ocurren en estos cambios? }\end{array}$ & $\begin{array}{l}\text { Explicar cuantitativa-mente la } \\
\Delta \mathrm{H}_{\mathrm{r}}^{\circ} \text { en un cambio tomando } \\
\text { como referencia el balance } \\
\text { entálpico de lo que ocurre con } \\
\text { los enlaces en un cambo físico } \\
\text { o químico. }\end{array}$ & $\begin{array}{l}\text { Saber interpretar la variación } \\
\text { entálpica, } \Delta \mathrm{H}_{\mathrm{r}}^{\circ} \text {, en varios cambios } \\
\text { conocidos (vaporización de un } \\
\text { líquido, disolución acuosa de una } \\
\text { sal, neutralización de ácido y base } \\
\text { fuertes, etc.). } \\
\text { Interpretar diagramas entálpicos en } \\
\text { procesos exotérmicos } \\
\text { endotérmicos }\end{array}$ \\
\hline
\end{tabular}


TABLA 2 (CONT.). Secuencia de situaciones problemáticas para el estudio de los efectos mecánicos y/o térmicos que suceden en los cambios físicos y químicos.

\begin{tabular}{|c|c|c|}
\hline $\begin{array}{l}\text { Secuencia de contenidos como } \\
\text { situaciones problemáticas a } \\
\text { plantear en Termoquímica }\end{array}$ & $\begin{array}{l}\text { Procedimientos sobre la } \\
\text { Ciencia a aprender por los } \\
\text { alumnos }\end{array}$ & $\begin{array}{lrr}\text { Valoraciones, } & \text { descripciones de } \\
\text { fenómenos } & y & \text { posibles } \\
\text { explicaciones } & & \\
\end{array}$ \\
\hline $\begin{array}{l}\text { 8. ¿Cómo predecir y contrastar } \\
\text { experimentalmente la variación de } \\
\text { entalpía estándar de un proceso, } \\
\Delta \mathrm{H}_{\mathrm{r}}^{\mathrm{o}} \text { ? }\end{array}$ & $\begin{array}{l}\text { Explicar macroscópicamente } \\
\text { la } \Delta \mathrm{H}^{\circ} \text { de un proceso a partir } \\
\text { de las entalpías estándar de } \\
\text { formación de las sustancias } \\
\text { que intervienen. }\end{array}$ & $\begin{array}{l}\text { Saber medir experimental-mente la } \\
\Delta \mathrm{H}_{\mathrm{r}} \text { estándar de un cambio físico o } \\
\text { químico que transcurre a presión } \\
\text { constante y, en particular, la entalpía } \\
\text { estándar de formación de una } \\
\text { sustancia compuesta }\left(\Delta \mathrm{H}_{\mathrm{f}}^{\mathrm{o}}\right) \text {. }\end{array}$ \\
\hline $\begin{array}{l}\text { 9. Saber las limitaciones del modelo } \\
\text { termodinámico utilizado. }\end{array}$ & Evaluar la validez del modelo. & $\begin{array}{l}\text { Saber que la variación de entalpía de } \\
\text { un proceso no equivaldrá al calor de } \\
\text { reacción a presión constante si } \\
\text { también se produce trabajo eléctrico } \\
\text { y/o radiaciones luminosas. }\end{array}$ \\
\hline $\begin{array}{l}\text { 10. Aplicación del modelo } \\
\text { estudiado a ejemplos de interés } \\
\text { personal o social como, puede ser: } \\
\text { saber si nuestra alimentación } \\
\text { favorece o no la obesidad. }\end{array}$ & $\begin{array}{l}\text { Contrastación del modelo de } \\
\text { explicación propuesto. Diseño } \\
\text { y realización de pruebas } \\
\text { experimentales o mediante } \\
\text { simulaciones informáticas. }\end{array}$ & $\begin{array}{l}\text { Saber aplicar los conocimientos a un } \\
\text { problema actual de interés como el } \\
\text { de la dieta personal para ver si es } \\
\text { saludable desde el punto de vista } \\
\text { energético. Necesidad de conocer el } \\
\text { índice de masa corporal (IMC) de la } \\
\text { persona y de qué factores depende. }\end{array}$ \\
\hline
\end{tabular}

Fuente: elaboración propia

\subsection{Ejemplos de actividades}

El programa de actividades sobre Termoquímica para el Bachillerato que se elaboró contenía 34 actividades y se implementó dentro del currículum de Didáctica de las Ciencias a los futuros profesores de Física y Química. Como ya se ha indicado se aplicó en dos cursos distintos con 18 y 17 de estos estudiantes universitarios agrupados en equipos de 4 o 3 durante un mes en el que debatían las actividades en clases de 2 horas de duración. Se presentan algunos ejemplos de actividades del programa de actividades y breves comentarios sobre los objetivos perseguidos y el tipo de estrategias utilizadas.

Actividad para diseñar y medir el calor producido en un proceso químico en una clase de Bachillerato

A.5.- Diseñad un experimento para ver si la neutralización de $\mathrm{NaOH}$ por $\mathrm{HCl}$ es un proceso exotérmico o endotérmico y, también, para medir el calor absorbido o producido.

Se trata de familiarizar a los estudiantes en el diseño de experimentos y superar obstáculos procedimentales tales como reconocer cuando un proceso es exotérmico o endotérmico, y, en particular, saber medir el calor absorbido o desprendido por el sistema en uno de estos procesos (apartado 2 de la tabla 2). En esta actividad se diseñó y realizó en clase un ejemplo de experimento de bajo coste utilizando como reactor una botella de plástico (figura 1). Los grupos de estudiantes obtuvieron resultados próximos a los de la bibliografía $\left(Q_{\text {ext }}=-13 \mathrm{kcal} / \mathrm{mol}\right)$ sin necesidad de incluir el cálculo del equivalente calorífico del reactor utilizado. 
IMAGEN 1. Experimento usado para cuantificar el calor de la neutralización entre $\mathrm{HCl}$ y $\mathrm{NaOH}$.

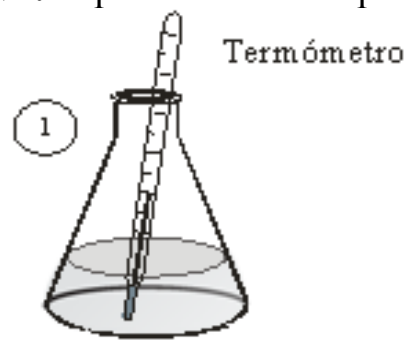

$50 \mathrm{ml}$ de $\mathrm{HCl} 1 \mathrm{M}$

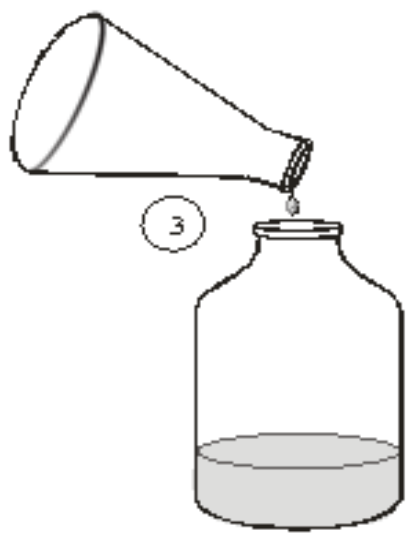

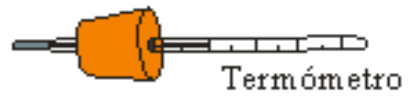
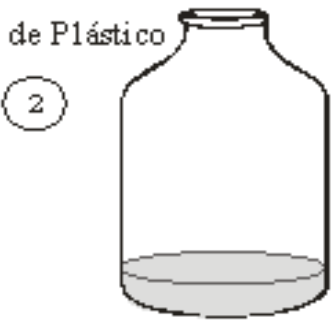

$50 \mathrm{~m} 1 \mathrm{de} \mathrm{NaOH} 1 \mathrm{MI}$

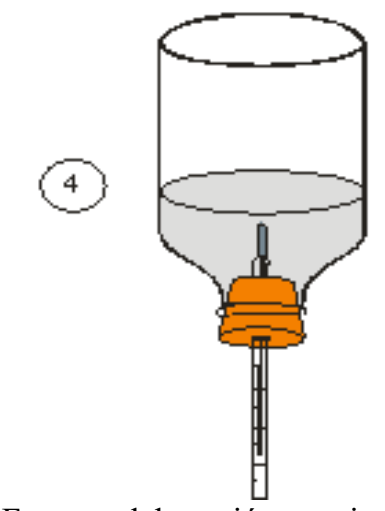

Fuente: elaboración propia

Actividad para emitir hipótesis sobre los factores de los que puede depender la energía interna previamente definida como función termodinámica de un sistema.

A.9.- Para explicar el calor producido en el cambio físico de una sustancia se ha introducido la función 'energía interna' del sistema como la suma del conjunto de energías cinéticas y potenciales asociadas a las partículas de una porción dada de la sustancia. ¿De qué factores pensáis que dependerá la energía interna del sistema constituido por esa porción de sustancia?

Tiene como objetivo reflexionar sobre el significado submicroscópico de la energía interna, E, del sistema que va a cambiar de estado (apartado 4 de la tabla 2). Por ejemplo, en el caso de la porción de sustancia que va a cambiar de estado se debatirá si su E dependerá de la masa (la cantidad de partículas que hay de la sustancia), la temperatura (relacionada con la energía cinética promedio de las partículas) y la estructura físico-química (en particular, el estado físico y la composición química relacionados con las energías potenciales asociadas a los enlaces intermoleculares e intramoleculares).

Actividad para explicar submicroscópicamente la variación de entalpía en un proceso endotérmico.

A.28.- Explicar, a título de hipótesis, la variación de entalpía que se produce cuando las moléculas de dos sustancias gaseosas como, por ejemplo, hidrógeno $\left(\mathrm{H}_{2}\right)$ y oxígeno $\left(\mathrm{O}_{2}\right)$ interaccionan formando nuevas moléculas $\left(\mathrm{H}_{2} \mathrm{O}\right)$. Se supone que el proceso es exotérmico.

En el debate se persigue revisar el modelo elemental de reacción química donde solamente los choques eficaces serán los de aquellas moléculas que al chocar tengan suficiente energía para superar la energía de activación, romper los enlaces de las moléculas de los reaccionantes y formar nuevas uniones atómicas en las moléculas de los productos (apartado 7 de la tabla 2). Conviene, con esta actividad, cuestionar la creencia de que la temperatura de un gas es debida a los choques entre sus partículas ya que se supone que son elásticos y, por tanto, sin ruptura de enlaces. Por otra parte, hay que suponer que cada uno de los enlaces atómicos en una molécula dada lleva asociada una entalpía estándar de formación y que para romper estos enlaces en la molécula se ha aportar desde el exterior dicha cantidad para que los choques sean eficaces. En cambio, al formarse los nuevos enlaces en las moléculas de los productos se liberarán sus respectivas entalpías estándar de formación aportadas por 
el propio sistema. En resumen, la suma de todas las entalpías de enlace (positivas cuando se rompan los enlaces en las moléculas de los reactivos y negativas cuando se forman los nuevos enlaces en las moléculas de los productos) nos darán la variación de entalpía estándar de todo el proceso que en este caso resultará positiva y, por tanto, será endotérmico (Chang, 1992).

\section{DISEÑO EXPERIMENTAL}

El programa de actividades se aplicó durante cuatro semanas en 12 sesiones de 2 horas durante dos cursos académicos consecutivos a dos grupos distintos de 18 y 17 estudiantes universitarios matriculados en Didáctica de las Ciencias. En total asistieron 35 estudiantes universitarios de los últimos cursos de los grados de Física $(\mathrm{N}=11)$, de Química $(\mathrm{N}=12)$ y de Ingeniería Química $(\mathrm{N}=12)$. En las clases estos futuros profesores de Física y Química de Bachillerato debatían las actividades de manera isomorfa a cómo habrían de enseñar el tema a alumnos de $2^{\circ}$ de Bachillerato. Para evaluar la eficacia de la secuencia de enseñanza implementada mediante el análisis del aprendizaje logrado, se elaboró un diseño pre-test/post-test que constaba de dos cuestionarios idénticos, $\mathrm{Q}_{1}$, con 5 ítems de preguntas abiertas en las que los estudiantes habían de predecir los efectos térmicos de varios procesos físicos y químicos y dar las explicaciones causales respectivas (Anexo 1).

El objetivo general del diseño es ver, por una parte, si los estudiantes universitarios tenían inicialmente dificultades para responder a los ítems de $\mathrm{Q}_{1}$ (pre-test) y, por otra, analizar si, después de implementar la secuencia de enseñanza, habían mejorado o empeorado sus respuestas en el posttest.

Los objetivos específicos de los ítems de $\mathrm{Q}_{1}$ son: a) en los ítems 1 y 2 se trata de ver si los estudiantes eran capaces de predecir la variación de temperatura del sistema en dos cambios físicos adiabáticos (la expansión de un gas aislado térmicamente y la evaporación rápida de un líquido volátil) y de explicarlas aplicando la primera ley de la Termodinámica en cada caso; b) en el ítem 3 se trata de ver si los estudiantes universitarios reconocen que la entalpía asociada a una sustancia depende, entre otros factores, de su estado físico y por ello se comparan las entalpías de formación del vapor y del agua líquida; c) en los ítems 4 y 5 tenían que explicar, respectivamente, el carácter exotérmico de la neutralización de ácido y base fuertes y el endotérmico de la síntesis del compuesto NO. En esta última explicación se pedirá que la hagan desde el punto de vista submicrocópico. Cada ítem se evaluará por dos investigadores. Las respuestas a cada ítem serán categorizadas como correctas o incorrectas separadamente por cada investigador atendiendo a criterios idénticos de evaluación. Solamente se clasificará cada respuesta como correcta si así lo acuerdan los dos expertos. En caso de disensiones en esta categorización dicotómica de las respuestas se ampliará el número de evaluadores. Además, al ser preguntas abiertas también se consideró interesante conocer sus dificultades conceptuales en el pre-test y categorizarlas. Esta segunda categorización nos permitirá verificar, al proponer el mismo cuestionario en el post-test, en qué medida ha habido mejora en la superación de aquellas dificultades. Y, una vez obtenidos los porcentajes de éxito en los cinco ítems de cada cuestionario, se verá si hay diferencias significativas entre el pre-test y el post-test calculando el parámetro $\chi^{2}$ empleada para el caso de variables dicotómicas correspondientes a grupos apareados y en tablas $2 \times 2$. Para ello se utilizará la expresión $\chi^{2}=\left[\left(\mathrm{N}_{1}-\mathrm{N}_{4}\right)\right]^{2} /\left(\mathrm{N}_{1}+\mathrm{N}_{4}\right)$ [5] para 1 grado de libertad, donde $\mathrm{N}_{1}$ es el número de estudiantes que han mejorado sus respuestas en el post-test y $\mathrm{N}_{4}$ es el de estudiantes que las han empeorado. Una vez determinado que existen diferencias significativas entre los resultados en el pre-test y en el post-test, se tratará de ver como son de intensas estas diferencias calculando en cada ítem el tamaño del efecto con el valor del coeficiente $\Phi$ según la ecuación $\Phi=\left(\chi^{2} /\right.$ $\mathrm{N})^{1 / 2}$ [6] (Welkovitz, Ewen y Cohen, 1986). Los valores experimentales de $\Phi$ que estén comprendidos entre 0 y 0.2 significará que el efecto logrado es débil, de 0.21 a 0.5 modesto, de 0.51 a 0.8 moderado y cuando es superior a 0.81 fuerte. 


\section{ANÁlisis DE RESULTADOS}

En primer lugar, se presentan y analizan los resultados encontrados en el pre-test categorizando las respuestas a los 5 ítems de $\mathrm{Q}_{1}$ en correctas e incorrectas y, al mismo tiempo, se presentarán las subcategorías de explicaciones incorrectas más frecuentes. En segundo lugar, se comparan las frecuencias de las subcategorías de explicaciones incorrectas con las obtenidas en el post-test para ver en qué medida han disminuido estas dificultades. Y, en tercer lugar, se darán las frecuencias globales $(\mathrm{N})$ de respuestas explicativas correctas obtenidas en el pre-test y el post-test así como la mejora neta $\left(\mathrm{N}_{1}\right)$ y el empeoramiento neto $\left(\mathrm{N}_{4}\right)$ de respuestas correctas en cada ítem con el fin de calcular la $\chi^{2}$ y el coeficiente $\Phi$ para determinar el tamaño del efecto logrado por la enseñanza.

\subsection{Resultados del pre-test}

En la tabla 3 se presenta la frecuencia global de las respuestas explicativas correctas y las frecuencias parciales de las subcategorías de respuestas incorrectas más frecuentes con ejemplos en cada uno de los 5 ítems del cuestionario Q1.

TABLA 3. Respuestas correctas e incorrectas más frecuentes en las explicaciones de los futuros profesores de Física y Química $(\mathrm{N}=35)$ en el pre-test.

\begin{tabular}{|c|c|c|c|c|}
\hline $\begin{array}{c}\text { Ítem } \\
\mathbf{N}^{\mathbf{o}}\end{array}$ & Contenido & $\begin{array}{c}\text { Respuestas } \\
\text { correctas }\end{array}$ & $\begin{array}{l}\text { Respuestas } \\
\text { incorrectas en } \\
\text { subcategoría i }\end{array}$ & $\begin{array}{c}\text { Subcategorías (i) de respuestas } \\
\text { incorrectas más frecuentes y } \\
\text { ejemplos. }\end{array}$ \\
\hline 1 & $\begin{array}{l}\text { ¿Qué le ocurre a } \\
\text { la temperatura de } \\
\text { un gas encerrado } \\
\text { en una jeringa } \\
\text { aislada } \\
\text { térmicamente que } \\
\text { se expansiona? }\end{array}$ & 4 & 15 (a) & $\begin{array}{l}\text { (a) Fijación funcional donde aplican la } \\
\text { ley de gases ideales. } \\
\text { Est. 27. PV/T=cte } \rightarrow \text { al aumentar } \\
V \rightarrow T \text { tiene que disminuir". } \\
\text { (b) Se aplica la misma ley de los gases } \\
\text { pero en el nivel submicroscópico. } \\
\text { Est. 8. "Disminuye la temperatura } \\
\text { porque disminuye el número de } \\
\text { choques entre las partículas al haber } \\
\text { mayor volumen y el mismo número de } \\
\text { partículas del gas". }\end{array}$ \\
\hline 2 & $\begin{array}{l}\text { ¿Qué le ocurre a } \\
\text { la tempera-tura } \\
\text { del éter líquido } \\
\text { que se evapora } \\
\text { rápidamente en } \\
\text { una cápsula } \\
\text { abierta? }\end{array}$ & 0 & $11(d)$ & $\begin{array}{l}\text { (c) Fijación funcional ( } \mathrm{T} \text { del éter no } \\
\text { varía). } \\
\text { Est. } 32 \text {. "Lo que se está produciendo } \\
\text { en la cápsula será la evaporación del } \\
\text { éter líquido, por tanto, lo que se } \\
\text { mediría en el termómetro sería la } \\
\text { temperatura de ebullición del éter que } \\
\text { permanece constante durante toda la } \\
\text { ebullición, y después alcanzará la } \\
\text { temperatura ambiental una vez finalice } \\
\text { la ebullición". } \\
\text { (d) El líquido para evaporarse requiere } \\
\text { calor de otro sistema (el entorno) o de } \\
\text { otro proceso. } \\
\text { Est. 6. "El éter está a una temperatura } \\
\text { inferior a la del ambiente ya que es } \\
\text { líquido y, por ello, se calienta. Y } \\
\text { finalmente se evapora". }\end{array}$ \\
\hline
\end{tabular}


TABLA 3 (CONT.). Respuestas correctas e incorrectas más frecuentes en las explicaciones de los futuros profesores de Física y Química $(\mathrm{N}=35)$ en el pre-test.

\begin{tabular}{|c|c|c|c|c|}
\hline $\begin{array}{c}\text { Ítem } \\
\mathbf{N}^{0}\end{array}$ & Contenido & $\begin{array}{c}\text { Respuestas } \\
\text { correctas }\end{array}$ & $\begin{array}{l}\text { Respuestas } \\
\text { incorrectas en } \\
\text { subcategoría i }\end{array}$ & $\begin{array}{c}\text { Subcategorías (i) de respuestas } \\
\text { incorrectas más frecuentes y } \\
\text { ejemplos. }\end{array}$ \\
\hline 3 & $\begin{array}{l}\text { ¿Cómo es la } \\
\text { entalpía del vapor } \\
\text { de agua que se } \\
\text { condensa respecto } \\
\text { de la del agua } \\
\text { líquida formada? }\end{array}$ & 3 & $5(\mathrm{~g})$ & $\begin{array}{l}\text { (e) Reduccionismos funcionales } \\
\text { macroscópicos donde la entalpía solo } \\
\text { depende de la sustancia o de la } \\
\text { temperatura. } \\
\text { Est. 12. "La entalpía del sistema solo } \\
\text { depende del tipo de sustancia y no del } \\
\text { estado de la sustancia". } \\
\text { (f) Reduccionismos funcionales sub- } \\
\text { microscópicos donde la entalpía de la } \\
\text { sustancia depende de la fuerza de los } \\
\text { enlaces sin justificarlo. } \\
\text { Est. 18. "Los enlaces en el gas son } \\
\text { más fuertes que en el líquido y por eso } \\
\text { la entalpía del gas es mayor que la del } \\
\text { líquido". } \\
\text { (g) Confusión entre entalpía y entropía. } \\
\text { Est. 9. "Creo que la entalpía del líquido } \\
\text { es mayor ya que en el gas las partículas } \\
\text { se mueven caóticamente y, por tanto, el } \\
\text { desorden aumenta y aumenta la } \\
\text { entropía. Por tanto, en el gas la } \\
\text { entalpía será menor que en el líquido". }\end{array}$ \\
\hline 4 & $\begin{array}{l}\text { ¿Es exotérmica o } \\
\text { endotérmica la } \\
\text { neutralización del } \\
\mathrm{HCl} \text { y el } \mathrm{NaOH} ? \\
\text { ¿Cómo se } \\
\text { explica? }\end{array}$ & 7 & $7(\mathrm{k})$ & $\begin{array}{l}\text { (h) Descripción fenomenológica sin } \\
\text { explicación macroscópica } \\
\text { submicroscópica. } \\
\text { Est. 6. "Si se observa un aumento de la } \\
\text { temperatura es porque la reacción } \\
\text { desprende energía en forma de calor y, } \\
\text { por tanto, es exotérmica". } \\
\text { (j) Explicación basada en la afinidad de } \\
\text { las sustancias que reaccionan. Est. } 13 \text {. } \\
\text { "Será exotérmica porque se desprende } \\
\text { calor. Se produce calor porque el } \\
\text { NaOH es una base fuerte y el HCl un } \\
\text { ácido fuerte, por ello la reacción entre } \\
\text { los dos es violenta y muy energética". } \\
\text { (k) Explicación submicroscópica } \\
\text { errónea. } \\
\text { Est. } 10 \text {. "Como hemos de romper } \\
\text { enlaces y se quedan iones en la } \\
\text { disolución necesitamos energía por lo } \\
\text { que es endotérmica y se manifiesta con } \\
\text { un aumento de T, los iones están libres } \\
\text { y con mavor energía". }\end{array}$ \\
\hline
\end{tabular}


TABLA 3 (CONT.). Respuestas correctas e incorrectas más frecuentes en las explicaciones de los futuros profesores de Física y Química $(\mathrm{N}=35)$ en el pretest.

\begin{tabular}{|c|c|c|c|c|}
\hline $\begin{array}{c}\text { Ítem } \\
\mathbf{N}^{\mathbf{0}}\end{array}$ & Contenido & $\begin{array}{c}\text { Respuestas } \\
\text { correctas }\end{array}$ & $\begin{array}{l}\text { Respuestas } \\
\text { incorrectas en } \\
\text { subcategoría i }\end{array}$ & $\begin{array}{c}\text { Subcategorías (i) de respuestas } \\
\text { incorrectas más frecuentes y } \\
\text { ejemplos. }\end{array}$ \\
\hline 5 & $\begin{array}{l}\text { ¿Cómo se } \\
\text { interpreta a nivel } \\
\text { submicroscópico } \\
\text { si la síntesis del } \\
\text { gas NO es } \\
\text { exotérmica o } \\
\text { endotérmica? }\end{array}$ & 3 & $8(\mathrm{~m})$ & 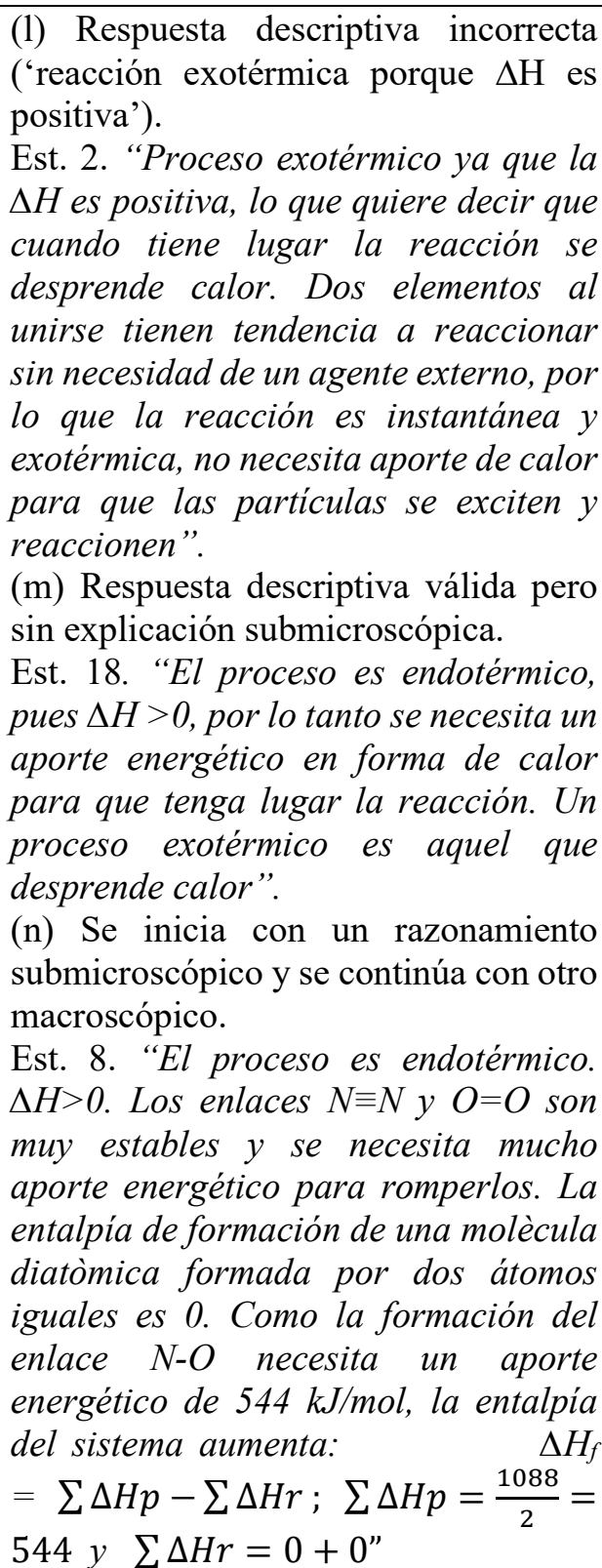 \\
\hline
\end{tabular}

Fuente: elaboración propia

Los resultados encontrados en el pre-test respecto a ejemplos de respuestas correctas se han expuesto en Furió-Gómez y Furió-Mas (2016). Las conclusiones de este trabajo muestran que los profesores de Física y Química en formación encuestados tienen serias dificultades conceptuales a la hora de utilizar los conceptos de energía interna y entalpía y la primera ley de la termodinámica para explicar fenómenos térmicos. A continuación, se transcriben las dificultades que se encontraron en las respuestas de estos estudiantes: a) No supieron delimitar cuáles son los sistemas o subsistemas que interaccionan en los dos procesos físicos (indicador 2). En el caso del ítem 1 la mayoría de las respuestas $(80 \%)$ no expresa que el gas realiza trabajo contra el ambiente y en las del ítem 2 no ha habido ninguna respuesta que tenga presente la transferencia energética entre la masa del interior del líquido y la de su superficie (indicador 3.1). b) En relación a precisar si los procesos en estos dos 
ítems son adiabáticos o casi adiabáticos (indicador 2), solamente ha habido un 17\% de las respuestas que lo han mencionado en el ítem 1 y $0 \%$ en las del ítem 2. c) Respecto al uso del termino 'energía interna' (indicador 3.2) solamente se ha citado por el 14\% de las respuestas en el ítem 1 y por el $0 \%$ en el ítem 2 y en ninguna respuesta de los ítems 1 y 2 se menciona al primer principio de la termodinámica (indicador 3.3). d) En el ítem 3 se presentan reduccionismos funcionales en el 33\% de las respuestas cuando indican que la entalpía de formación de una sustancia solamente depende de la temperatura o de la sustancia. e) Es importante destacar que en los ítems 4 y 5 relativos a las explicaciones sobre el carácter exotérmico o endotérmico de los dos procesos químicos hemos encontrado respuestas erróneas al desconocer el convenio de signos aceptado: el 25\% describe la neutralización como endotérmica 'ya que el sistema se calienta' y el 37\% considera que la síntesis de NO es exotérmica porque 'hay que calentar el sistema' (indicador 1). f) Por otra parte, se presentan algunos razonamientos del tipo 'la ruptura de enlaces en los reactivos produce energía o calor' y 'la formación de enlaces requiere un aporte exterior de energía o calor' (indicador 4.2). g) La mayoría de estos estudiantes conocían que la neutralización entre $\mathrm{HCl}$ y $\mathrm{NaOH}$ era un proceso exotérmico pero en ninguna respuesta se citaba qué enlaces se rompían y cuáles se formaban en el proceso (indicador 4.1). h) En el caso de la síntesis del NO se destaca que la mayoría de las respuestas incorrectas (37\%) indica que el proceso es exotérmico pero algunos que sabían que era endotérmico (11.6\%) dieron una explicación incorrecta mezclando los niveles submicroscópico y macroscópico de representación (indicador 4.1).

\subsection{Comparación del pre-test y el post-test}

Una vez implementada la secuencia de enseñanza se volvió a aplicar el cuestionario Q 1 (posttest) a la muestra de futuros profesores para ver, primero, en qué medida se habían superado las dificultades categorizadas anteriormente en el pre-test (tabla 4) y, después, el tamaño del efecto logrado en la implementación (tabla 5).

A continuación, se exponen comentarios con las principales observaciones sobre la tabla 4:

a) En el ítem 1 sigue habiendo un uso pertinaz de la ecuación de los gases perfectos en las soluciones dadas por los estudiantes puesto que las $2 / 3$ de los que se equivocaron en el pretest continúan incidiendo en el mismo error en el post-test.

b) En cambio, el mayor éxito de los estudiantes en el ítem 2 ha sido debido a que la mayoría de ellos utilizaron razonamientos submicroscópicos sencillos del tipo: 'las partículas más rápidas (otros decían 'calientes') de la superficie del éter se escapan a la atmósfera y, por tanto, es como si hubiera una transferencia de energía del interior del líquido hacia el exterior'.

c) En el ítem 4 todavía queda 1/3 de la muestra que no han superado sus dificultades que se explica porque la mayoría de ellos pertenecen a la submuestra de estudiantes de Física que alegan no haber estudiado Química en su currículum.

d) Sin embargo, en el ítem 5 ha disminuido notablemente la cantidad de errores (han pasado de 24 a 4) debido a que se ha considerado como correcto el argumento del balance energético en la formación y ruptura de enlaces en productos y reaccionantes, respectivamente, si bien se debía haber usado el balance entálpico. En efecto, la mayoría de estos estudiantes ha argumentado como respuesta prototípica que 'romper los enlaces en los reactantes ha costado más energía que la liberada al formarse el producto'. 
TABLA 4. Comparación de las frecuencias de respuestas incorrectas obtenidas en cada ítem en el pre-test y en el post-test.

\begin{tabular}{|c|c|c|c|}
\hline Ítem & $\begin{array}{l}\text { Subcategorías (i) de respuestas incorrectas en } \\
\text { el pre-test }\end{array}$ & $\begin{array}{l}\text { Respuestas } \\
\text { incorrectas en } \\
\text { el pre-test }\end{array}$ & $\begin{array}{l}\text { Respuestas } \\
\text { incorrectas en } \\
\text { el post-test }\end{array}$ \\
\hline 1 & $\begin{array}{l}\text { (a) Aplicación macroscópica de la ecuación de } \\
\text { gases ideales. } \\
\text { (b) Aplicación submicroscópica de la ecuación de } \\
\text { los gases ideales. }\end{array}$ & $\begin{array}{l}15(\mathrm{a}) \\
10(\mathrm{~b})\end{array}$ & $\begin{array}{l}11 \text { (a) } \\
7 \text { (b) }\end{array}$ \\
\hline 2 & $\begin{array}{l}\text { (c) Fijación funcional: la temperatura del éter no } \\
\text { varía porque hierve. } \\
\text { (d) El líquido para evaporarse requiere calor de otro } \\
\text { sistema o proceso. }\end{array}$ & $\begin{array}{l}19(\mathrm{c}) \\
11(\mathrm{~d})\end{array}$ & $\begin{array}{l}2(\mathrm{c}) \\
2(\mathrm{~d})\end{array}$ \\
\hline 3 & $\begin{array}{l}\text { (e) Reduccionismos funcionales macroscópicos: la } \\
\text { entalpía depende solo de la sustancia o solo de la } \\
\text { temperatura. } \\
\text { (f) Reduccionismos funcionales submicroscópicos } \\
\text { donde la entalpía de la sustancia depende de la } \\
\text { fuerza de los enlaces sin justificarlo. } \\
\text { (g) Confusión entre entalpía y entropía. }\end{array}$ & $9(\mathrm{f})$ & $\begin{array}{l}4(\mathrm{f}) \\
3(\mathrm{~g})\end{array}$ \\
\hline 4 & $\begin{array}{l}\text { (h) Descripción fenomenológica sin explicación } \\
\text { macroscópica ni submicroscópica. } \\
\text { (j) Explicación basada en la afinidad de las } \\
\text { sustancias que reaccionan. } \\
\text { (k) Explicación submicroscópica errónea. }\end{array}$ & $\begin{array}{l}12(\mathrm{~h}) \\
5(\mathrm{j}) \\
7(\mathrm{k})\end{array}$ & $\begin{array}{l}8(\mathrm{~h}) \\
3(\mathrm{j}) \\
2(\mathrm{k})\end{array}$ \\
\hline 5 & $\begin{array}{l}\text { (1) Reacción exotérmica porque } \Delta \mathrm{H}^{\circ} \text { es positiva. } \\
\text { (m) Respuesta descriptiva válida pero sin } \\
\text { explicación submicroscópica. } \\
\text { (n) Mezcla de razonamientos macroscópicos y } \\
\text { submicroscópicos }\end{array}$ & $\begin{array}{l}13(1) \\
8(\mathrm{~m}) \\
4(\mathrm{n})\end{array}$ & $\begin{array}{l}2(1) \\
2(\mathrm{~m}) \\
0(\mathrm{n})\end{array}$ \\
\hline
\end{tabular}

Fuente: elaboración propia

En la tabla 5 se presentan los resultados globales de respuestas correctas en los ítems de $\mathrm{Q}_{1}$ en el pre-test y en el post-test, el número de estudiantes $\left(\mathrm{N}_{1}\right)$ que han mejorado su respuesta pasando de la categoría de incorrecta a correcta y el número de estudiantes $\left(\mathrm{N}_{4}\right)$ que la han empeorado al pasar de la categoría de correcta en el pre-test a incorrecta en el post-test. A partir de estos datos se han obtenido los valores correspondientes a $\chi^{2}$, para 1 grado de libertad, y los del tamaño del efecto conseguido (coeficiente $\Phi$ ) para cada ítem que también constan en esta tabla 5.

Así pues, se concluye que la instrucción ha sido moderadamente eficaz respecto a la mejora de los conocimientos previos de la primera ley de la termodinámica y del concepto de entalpía en termoquímica que tenían los futuros profesores de Física y Química dado que el tamaño del efecto en los ítems 2,3 y 5 han sido moderados $(\Phi>0.5)$ lo que refleja que hay una relación significativa entre la mejora lograda en los aprendizajes y la enseñanza impartida. En cambio, la mejora ha sido modesta en los ítems 1 y 4 . En efecto el ítem $\mathrm{n}^{\circ} 1(\Phi=0.4)$ sigue siendo difícil de resolver correctamente para las $2 / 3$ partes de la muestra en el post-test al no saber aplicar la primera ley de la Termodinámica y el ítem $n^{\circ} 4(\Phi=0.5)$ también lo ha sido para la mitad de la muestra, en este caso por desconocimiento químico, en particular, en los estudiantes de Física de la muestra. 
TABLA 5. Frecuencia global de respuestas correctas en el pre-test y el post-test y número de estudiantes que han mejorado $\left(\mathrm{N}_{1}\right)$ y que han empeorado $\left(\mathrm{N}_{4}\right)$.

\begin{tabular}{|c|c|c|c|c|c|c|c|}
\hline Ítem & $\begin{array}{c}\text { Respuestas } \\
\text { correctas } \\
\text { pre-test }\end{array}$ & $\begin{array}{c}\text { Respuestas } \\
\text { correctas } \\
\text { post-test }\end{array}$ & $\begin{array}{c}\text { Respuestas que } \\
\text { han mejorado } \\
\left(\mathbf{N}_{\mathbf{1}}\right)\end{array}$ & $\begin{array}{c}\text { Respuestas } \\
\text { que han } \\
\text { empeorado } \\
\left(\mathbf{N}_{4}\right)\end{array}$ & $\chi^{\mathbf{2}}$ & $\mathbf{p}$ & $\begin{array}{c}\text { Tamaño del } \\
\text { efecto } \\
(\Phi)\end{array}$ \\
\hline 1 & 4 & 12 & 9 & 1 & 4.9 & 0.03 & 0.4 \\
\hline 2 & 0 & 28 & 28 & 0 & 26.0 & $3 \cdot 10^{-7}$ & 0.7 \\
\hline 3 & 3 & 20 & 18 & 1 & 13.5 & $2 \cdot 10^{-4}$ & 0.6 \\
\hline 4 & 7 & 18 & 16 & 1 & 11.5 & $7 \cdot 10^{-4}$ & 0.5 \\
\hline 5 & 3 & 29 & 26 & 0 & 24.0 & $10^{-6}$ & 0.6 \\
\hline
\end{tabular}

Fuente: elaboración propia

\section{CONCLUSIONES}

Respecto a la primera pregunta de la investigación se ha constatado en el pre-test que la mayoría de la muestra de profesores de Física y Química en formación presentan serias dificultades conceptuales en la aplicación de la primera ley de la termodinámica, así como en el concepto de entalpía para explicar los efectos térmicos. Dificultades que se han ejemplificado en la tabla 1. Por otra parte, se ha constatado empíricamente que la mayor parte de los indicadores de aprendizaje propuestos en la tabla 1 pueden servir para evaluar los conocimientos termoquímicos adquiridos.

Respecto a la segunda pregunta relativa a si es posible mejorar los conocimientos de estos profesores en formación se ha de resaltar que más de la mitad de estos estudiantes han afianzado sus conocimientos termoquímicos que tenían olvidados y, al mismo tiempo, han vivido un nuevo enfoque de la enseñanza basado en la indagación que podrán aplicar como profesores. No obstante, se ha de reconocer que, al menos en dos ítems ( 1 y 4 del post-test) todavía subsisten dificultades y, por tanto, habría de modificarse el programa de actividades. Por ejemplo, en el ítem 1 del post-test 23 de los futuros profesores sigue sin aplicar la primera ley y, aunque la mayoría de ellos relaciona el enfriamiento del gas con su expansión adiabática, no llegan a explicitar que el gas realiza trabajo contra el entorno a costa de la disminución de su energía interna. En cambio, la mayoría de las respuestas correctas $(\mathrm{N}=26)$ en el ítem 2 del post-test sobre evaporación del éter han aplicado el modelo submicroscópico que el enfriamiento del éter ha sido debido al 'escape de la superficie del líquido de las moléculas más rápidas'. En el ítem 3 del post-test ha aumentado en 17 (49\%) las respuestas correctas y ha disminuido en un $62 \%$ (de 21 a 8) la idea errónea de que la entalpia del agua no depende del estado físico. En el ítem 4 del post-test solamente la mitad de la muestra $(\mathrm{N}=18)$ respondieron correctamente y del resto, 8 estudiantes de Física justificaron que no habían podido dar una explicación correcta debido a la ausencia de Química en su currículum. En cambio, en el ítem 5 del post-test el número de respuestas correctas ha sido 29 estudiantes (83\%) los que han usado correctamente la explicación submicroscópica del balance energético de ruptura y formación de enlaces en la síntesis del NO. La mayoría de los futuros profesores de la muestra, en una autovaloración posterior al post-test que no hemos incluido en este trabajo, indicaron que el uso del 
nivel submicroscópico aumentó su comprensión, sobre todo, para explicar los efectos térmicos en los procesos químicos.

Una implicación importante de este trabajo es la necesidad de mejorar la formación inicial de estos futuros profesores de Física y Química y para ello es importante que, en primer lugar, acaben sus grados con un buen conocimiento conceptual y epistemológico del contenido de Física y de Química que han de enseñar en la educación secundaria y en el bachillerato. Los resultados de la investigación en didáctica de las ciencias han mostrado que la primera competencia profesional docente es la de saber la disciplina. En el caso de la termoquímica será muy conveniente que los profesores de Física y Química conozcan bien la modelización termodinámica macroscópica y que sepan complementarla con la modelización atómica-molecular para explicar fenómenos térmicos ya que así aumentará la comprensión de sus estudiantes. Una segunda implicación didáctica de este trabajo es mostrar cuán importante es integrar la reflexión explícita de los futuros profesores mediante la vivencia de propuestas innovadoras que están resultando eficaces según la investigación. Es muy conveniente que los futuros profesores experimenten estas innovaciones metodológicas de manera isomorfa a como tendrían que implementarlas en una clase de Bachillerato y aprendan a integrar la evaluación en la enseñanza, por ejemplo, aprovechando los exámenes para mejorar el aprendizaje (Yerushaldi, Cohen, Mason y Singh, 2012). Finalmente también es importante implicarles poco a poco en investigaciones de diseño curricular donde se planteen como elaborar una secuencia de enseñanza: saber seleccionar y organizar estos contenidos en un nivel educativo dado, qué objetivos de aprendizaje y dificultades se pueden presentar, qué estrategias instructivas emplear en su implementación y cómo evaluar si se logran los objetivos perseguidos en la enseñanza con el fin de mejorarla (Guisasola, Zuza, Ametller y Gutierrez-Berraondo, 2017).

\section{Referencias}

Al-Balushi, S.M. (2009). Factors influencing pre-service science teachers' imagination at the microscopic level in chemistry. International Journal of Mathematical Education in Science and Technology, 7, 1089-1110. DOI:10.1007/s10763-009-9155-1

Atkins, P.W. (1992). La segunda ley. Barcelona: Prensa Científica, S.A.

Bain, K., Moon, A., Mack, M.R. y Towns, M.H. (2014). A review of research on the teaching and learning of thermodynamics at the university level. Chemistry Education Research and Practice, 15, 320-335. DOI: 10.1039/C4RP00011K

Barlet, R. y Mastrot, G. (2000). L'alghorithmisation-refuge, obstacle à la conceptualisation. L'exemple de la thermochimie en premier cycle universitaire. Didaskalia, 17, 123-159.

Blackburn, V., y Moissan, C. (1986). The in-service training of teachers in the twelve Member States of the European Communities. Maastrich: Presses interuniversitaires européennes.

Chang, R. (1992). Química (4 edición). México: McGraw-Hill.

Doménech, J.L., Limiñana, R. y Menargues, A. (2013). La superficialidad en la enseñanza del concepto de energía: una causa del limitado aprendizaje alcanzado por los estudiantes de Bachillerato. Enseñanza de las Ciencias, 31(3), 103-119.

Furió C., Azcona, R. y Guisasola J. (2006). Enseñanza de los conceptos de cantidad de sustancia y de mol basada en el modelo de aprendizaje como investigación orientada. Enseñanza de las Ciencias, 24(1), 43-58.

Furió C., Calatayud M.L., Bárcenas S.L. y Padilla, O.M (2000). Functional fixedness and functional reduction as common sense reasonings in chemical equilibrium and in geometry and polarity of molecules. Science Education, 84, 545-565. DOI: 10.1002/1098237X(200009)84:5\%3C545::AID-SCE1\%3E3.0.CO;2-1

Furió C., Guisasola J., Almudí J.M. y Ceberio M.J. (2003). Learning the electric field concept as oriented research activity. Science Education, 87, 640-662. DOI: 10.1002/sce.10100 
Furió-Gómez, C. y Furió-Más, C.(2016). Dificultades conceptuales y epistemológicas de futuros profesores de Física y Química en las explicacions energéticas de fenómenos físicos y químicos. Enseñanza de las Ciencias, 34(3), 7-24. DOI: 10.5565/rev/ensciencias. 1644

Furió-Más, C., Solbes-Matarredona, J. y Furió-Gómez, C. (2008). Towards a proposal for effective ongoing training programmes for science teachers. Problems of Education in the 21st century, 6, 60-70.

Granville, M.F. (1985). Student misconceptionss in Thermodynamics. Journal of Chemical Education, 62(10), 847-848. DOI: 10.1021/ed062p847

Guisasola, J., Furió, C. y Ceberio, M. (2008). Science Education based on Developing Guided Research. En M.V. Thomase (Ed.), Science Education in Focus (pp. 173-202). Nueva York: Nova Science Publishers, Inc.

Guisasola, J., Zuza, C., Ametller, J. y Gutierrez-Berraondo, J. (2017). Evaluating and redesigning teaching learning sequences at the introductory physics level. Physics Review Physics Education Research, 13, 020139. DOI: 10.1103/PhysRevPhysEducRes.13.020139

Hadfield, L.C. y Wieman, C.E. (2010). Student interpretations of equations related to the first law of thermodynamics. Journal of Chemical Education, 87(7), 750-755. DOI: 10.1021/ed1001625

Kermen, I. y Meheut, M. (2011). Grade 12 french students'use of a thermodynamic model for predicting the direction of incomplete chemical changes. International Journal of Science Education, 33(13), 1745-1773. DOI: 10.1080/09500693.2010.519008

Loverude, M.E., Kautz, C.H. y Heron, P.R. (2002). Student understanding of the first law of thermodynamics: Relating work to the adiabatic compression of an ideal gas. American Journal of Physics, 70(2), 137-148. DOI: 10.1119/1.1417532

N.R.C. (2000). Inquiry and the National Science Education Standards: A Guide for Teaching and Learning. Washington D.C.: National Academic Press.

N.R.C. (2011). A Framework for K-12 Science Education Standards: A Guide for Teaching and Learning. Washington D.C.: National Academic Press.

Nilson, T. y Niedderer, H. (2014). Undergraduate students' conceptions of enthalpy, enthalpy change and related concepts. Chemistry Education Research and Practice, 15, 336-353. DOI: $10.1039 / \mathrm{C} 2 \mathrm{RP} 20135 \mathrm{~F}$

Rocard, M., Csermely, P., Jorde, D., Lenzen, D., Walberg-Henriksson, H. y Hemmo, V. (2007). Science education now: A renewed pedagogy for the future of Europe. Report to the European Commission of the expert group on science education. Recuperado de https://ec.europa.eu/research/science-society/document_library/pdf_06/report-rocard-onscience-education en.pdf [10 de febrero de 2020].

Solbes, J., Guisasola, J. y Tarín, F. (2009). Teaching energy conservation as a unifying principle in physics. Journal of Science Education and Technology, 18(3), 265-274. DOI: 10.1007/s10956009-9149-3

Sreemivasulu, B. y Subramaniam, R. (2013). University students' understanding of chemical thermodynamics. International Journal of Science Education, 35(4), 601-635. DOI: 10.1080/09500693.2012.683460

Talanquer, V. (2006). Commonsense chemistry: a model for understanding students' alternative conceptions. Journal of Chemical Education, 83(5), 811-816. DOI: 10.1021/ed083p811

Treagust, D.F., Chittleborough, G. y Mamiala, T.L. (2003). The role of submicroscopic and symbolic representations in chemical explanations. International Journal of Science Education, 25(11), 1353-1368. DOI: 10.1080/0950069032000070306

Viennot, L. (1992). Raisonnement à plusieurs variables: tendances de la pensée commune. Aster, 14, 127-141.

Welkovitz, J., Ewen, R.B. y Cohen, J. (1986). Estadística aplicada a las ciencias de la educación. Madrid: Ed. Santillana: Aula XXI. 
Yerushaldi, E., Cohen, E., Mason, A. y Singh, C. (2012). What do students do when asked to diagnose their mistakes? Does it help them? An atypical quiz context. Physical Review Physics Education Research, 8(2), 020109. DOI: 10.1103/PhysRevSTPER.8.020109

\section{Cómo CITAR ESTE ARTÍ́CULO}

Furió, C., Furió, C. y Guisasola, J. (2020). Evaluación de una secuencia de enseñanza de termoquímica para la formación de profesores. Didáctica de las ciencias experimentales y sociales, 38, 133-152. DOI: 10.7203/DCES.38.15577. 


\section{Anexo \\ Cuestionario sobre Termoquímica aplicado al grupo experimental de futuros profesores de Física y Química}

1. El dibujo adjunto presenta una jeringa aislada térmicamente del ambiente que contiene un gas ideal a presión mayor que la atmosférica. ¿Qué le pasará a la temperatura del gas cuando se expansione?
(a) Disminuye la temperatura.
(b) Se mantiene la temperatura.
(c) Aumenta la temperatura.
(d) No lo sé.

Justifica detalladamente el porqué de la respuesta.

2. Si en una cápsula de porcelana ponemos éter líquido a temperatura ambiente podemos comprobar que al evaporarse rápidamente varía la temperatura del líquido. Indica si:
(a) Disminuye la temperatura.
(b) Se mantiene la temperatura.
(c) Aumenta la temperatura.
(d) No lo sé.
Explica con detalle tu respuesta.

3. Consideremos la transformación de un gas en líquido a la misma temperatura:

$\mathrm{H}_{2} \mathrm{O}(\mathrm{g}) \rightarrow \mathrm{H}_{2} \mathrm{O}(\mathrm{l})$

¿Qué estado de la sustancia tendrá una mayor entalpía?
(a) La entalpía del gas es mayor.
(b) La entalpía del líquido es mayor.
(c) Las entalpías del líquido y del gas son iguales.
(d) No lo sé

Argumenta razonadamente tu respuesta.

4. Al neutralizar una disolución de $\mathrm{NaOH}$ con otra de $\mathrm{ClH}$, en el líquido resultante se observa un aumento de temperatura. Indica si la reacción es exotérmica o endotérmica y explica con detalle cómo es que se produce este fenómeno térmico.

La variación de entalpía en la reacción de formación del monóxido de nitrógeno viene expresada en la siguiente ecuación: $\mathrm{N}_{2}(\mathrm{~g})+\mathrm{O}_{2}(\mathrm{~g}) \rightarrow 2 \mathrm{NO}(\mathrm{g}) ; \Delta \mathrm{H}=1088 \mathrm{~kJ}$. Indica si el proceso es exotérmico o endotérmico y explica submicroscópicamente como es que aumenta la entalpía del sistema al formarse el monóxido de nitrógeno. 